\title{
City climate and landscape structure shape pollinators, nectar and transported pollen along a gradient of urbanization
}

Paolo Biella ${ }^{1 *}$, Nicola Tommasi ${ }^{1}$, Lorenzo Guzzetti ${ }^{1}$, Emiliano Pioltelli $^{1}$, Massimo Labra ${ }^{1}$, Andrea Galimberti ${ }^{1}$

1 University of Milano-Bicocca, Department of Biotechnology and Biosciences, ZooPlantLab, Piazza della

Scienza 2, 20126, Milan, Italy. *Corresponding author: Paolo Biella, paolo.biella@unimib.it

\section{Abstract}

1. Urbanization gradients influence both landscape and climate and provide opportunity for understanding how species, especially plants and pollinators, respond to artificially driven environmental transitions.

2. Here, we investigated several aspects of pollination along an urbanization gradient in landscape and climate. We quantified wild hoverfly and bee abundances with trapping, standing crop of nectar with spectrophotometer, and the pollen transported by flower-visitors with DNA-metabarcoding, in 40 independent sites from seminatural to built-up areas in Northern Italy.

3. Linear and nonlinear relationships were detected along the urbanization gradient. Pollinator abundances increased until $22 \%$ of impervious surface, dropping by $34 \%$ after that, and it also decreased with green patch distance and urban park size. Thus, suburban landscapes host more pollinators than highly cemented or seminatural areas. Moreover, pollinators diminished by up to $45 \%$ in areas with low temperature seasonality: urbanized areas likely posing thermic stress. Furthermore, the sugar mass available in nectar increased by $91 \%$ with impervious cover, indicating that city nectars were less consumed or flowers more productive. Furthermore, the species richness of pollen decreased by $32 \%$ in highly urbanized areas, and with a high incidence of exotic plants, hinting for anthropized plant communities.

4. Synthesis and applications. Urbanization influences pollinator abundances, nectar resources and transported pollen. Pollinators are negatively affected by a thermally harsh climate in highly urbanized areas with isolated green areas and large parks. Suburban landscapes demonstrated the highest pollinator presence. In the city core, flowers contained more nectary sugar, while pollinators collected pollen from a small number of plants, mainly exotic. These findings highlight the influence of urban landscape structure and climate on pollinators and plants, showing that cities are heterogenous realities. Patterns from this study will serve as basis for pollinator-friendly planning and management of urban landscapes. 


\section{Introduction}

Given the environmental change caused by cemented and built-up surfaces in contrast to adjacent ecosystems, urban areas are often considered as a separate macrohabitat for animal and plant communities (Bolger et al. 2000; Faeth and Kane 1978). Cities provide an artificial environment that creates an extreme transition (Lemoine-Rodríguez et al. 2020), causing several types of responses on biodiversity. These impacts affect a number of ecosystem processes (Mclntyre et al. 2001), mainly by influencing changes in species interactions (Cohen et al. 2020; Geslin et al. 2013). As plants and pollinators play key roles in many ecosystem processes (Patel et al. 2020; Potts et al. 2016), gaining an understanding of how urbanization gradients shape aspects of pollination and pollinator ecology is of utmost importance.

Urbanization can be described as a gradient, with different consequences for plants and pollinators. For instance, plant diversity is higher at moderate urbanization (McKinney 2008), and suburban areas host higher wild bee and butterfly diversity than the city core (Banaszak-Cibicka and Żmihorski 2020; Kurylo et al. 2020). Surprisingly, the potential beneficial aspects of suburban landscapes on pollinator and plant communities has rarely been pointed out to-date (Wenzel et al. 2020; Harrison and Winfree 2015). Moreover, different pollinator types and life-history traits respond differently to urbanization (Wenzel et al. 2020) in spite of a generally high variation among studies (Buchholz and Egerer 2020). For instance, less Diptera Syrphidae than Hymenoptera are expected to occur in cities (Persson et al. 2020). Within Hymenoptera, built environments may change the composition of bee assemblages, with a high occurrence of solitary and above-ground nesting bees (Wilson and Jamieson 2019), while filtering big species out (Buchholz and Egerer 2020). Furthermore, fragment isolation may play a role, as a study found poorer pollinator assemblages in more isolated urban green areas (Tonietto et al. 2011). All these aspects highlight the need to further explore how pollinators respond to structural differences in urbanized landscapes.

Cities transform not only landscapes but they also directly impact local climates (Kuttler 2008), thus likely triggering species physiological responses, even in plants and pollinators. Urban climate is are usually warmer, it holds lower relative humidity and has higher precipitation than the surroundings (Kuttler 2008). The urban heat island effect determines both high temperatures and lower temperature seasonality, a 
phenomenon that lasts both daily and across seasons (Marando et al. 2019). For instance, warmer cities impact plant physiology and phenology, triggering earlier flowering (Fisogni et al. 2020; Neil and Wu 2006). Also pollinator physiology can be affected (Hamblin et al. 2018). Intriguingly, a recent study showed that bees inhabiting city cores have higher thermic stress (Burdine and McCluney 2019). It is likely that the climatic impact posed by cities on plant and pollinator physiology are directly connected to patterns of diversity and abundances of those assemblages (Chown and Duffy 2015; Diamond et al. 2015). This is exemplified by studies showing that climatic features could affect some families of bees even more than landscape alteration (Kammerer et al. 2021). Therefore, it seems relevant to describe the responses of plants and pollinators not only as a function of city landscape alone but also by urban climatic variation.

In this study, we evaluated the effects of urbanization on several aspects of pollination and pollinator ecology, which are also relevant for ecosystem functioning (Biella, Akter, et al. 2019; Patel et al. 2020). We surveyed along a gradient of increasing urbanization in Northern Italy, a region characterized by a high proportion of built-up surfaces and remarkable climatic shift due to urban areas (Perini and Magliocco 2014). In order to address a mechanistic understanding of how an artificial gradient shapes pollination ecology and to connect local surveys to the structure of the surrounding area, we characterized landscape composition, its configuration and the climate.

We tested factors that were specifically selected based on hypothesized direct effects. Firstly, we measured pollinator abundance, as an indicator of habitat suitability (Bartholomée et al. 2020) and hypothesized that, along the urbanization gradient, pollinators may be dependent on the distribution and accessibility of suitable areas measured here as proportion of impervious cover and isolation of green spaces used for foraging (Steffan-Dewenter and Tscharntke 1999). Within the context of the highly urbanized area, we also tested the role of city park size in order to further highlight the relationship with patch size as larger areas might serve as refugia for larger populations (Baldock et al. 2019). In addition, temperature variation along the urbanization gradient could impact flower visiting organisms and also determine their local abundance (Burdine and McCluney 2019; Hamblin et al. 2018) by affecting pollinator physiology (Colinet et al. 2015). Secondly, we characterized the availability of nectar sugar mass, because nectar constitutes one of the main 
resources collected by flower visitors (Hicks et al. 2016). The reward quantity along the gradient would mainly be due to the secretion rate and thus to plant physiology, and its amount is partly determined by pollinator foraging rate (Corbet 2003). We hypothesize that the available nectar quantity could depend on the size of green areas because bigger patches may host richer communities(Collins et al. 2009; Dauber et al. 2010). In addition, plant productivity is often driven by precipitation and by the length of the thermally suitable season for growing, climatic parameters that vary with urbanization and that could impact nectar production (Mueller et al. 2020; Zipper et al. 2016). Thirdly, we considered the pollen diversity carried by flower-visitors, that were used here as a passive surveying of plant richness from the pollinator perspective (Biella, Tommasi, et al. 2019). In other words, we quantified the number of plant species visited by pollinators by studying the transported pollen, that is an important component of the total pollination rate (Bosch et al. 2009). Moreover, the advantage of using pollinators as passive samplers lies on the difficulty of sampling the vegetation of complex urban structures (e.g. tall buildings, balconies and private gardens) that impede traditional survey techniques. Here we described the transported pollen richness along the urbanization gradient (hence in relation to the impervious cover) and we also expected an influence by green-patch sizes, as it may determine local plant diversity (Collins et al. 2009; Dauber et al. 2010). We did not analyze climatic variables in this case as in anthropogenic areas pollen availability could be influenced by management (Aronson et al. 2017; Ibsen et al. 2020).

\section{Materials and methods}

\section{Study area}

Study sites were set in Northern Italy, mainly in the region surrounding Milan (Fig. 1) that is occupied by urbanized surfaces (about $38 \%$ of the area), intensive agricultural environments (ca. 53\%), and natural forests, wet habitats and seminatural hay meadows (ca. 9\%) (Regione Lombardia and ERSAF 2010). Study site locations were selected randomly with a GIS software (QGIS 3.6.2) and were distributed in an area of 1575 $\mathrm{km}^{2}$ over a surface including the entire region of Milan and the urban parks of Milan city. We applied a minimum of $1 \mathrm{~km}$ distance between points to assure the independency of sampling sites (Phillips et al. 2019), 
bioRxiv preprint doi: https://doi.org/10.1101/2021.10.15.464497; this version posted October 16, 2021. The copyright holder for this preprint (which was not certified by peer review) is the author/funder, who has granted bioRxiv a license to display the preprint in perpetuity. It is made available under aCC-BY-NC 4.0 International license.

later confirmed by an autocorrelation analysis resulting not significant when testing correlation of putative predictors with themselves with Moran's I (P value $>0.05)$. We adjusted the exact sampling locations so that each would be located in either a urban park surrounded by "impervious" surfaces (i.e., concrete, asphalt, buildings) or at the margins of agricultural fields with a varying quantity of surrounding impervious surface or in seminatural hay meadows near forests $(<1 \mathrm{~km})$ with little amount of urbanization nearby (Fig. S1).

Overall, 40 sites were surveyed, across the entire urbanization gradient (Fig. 1, Fig. S1).

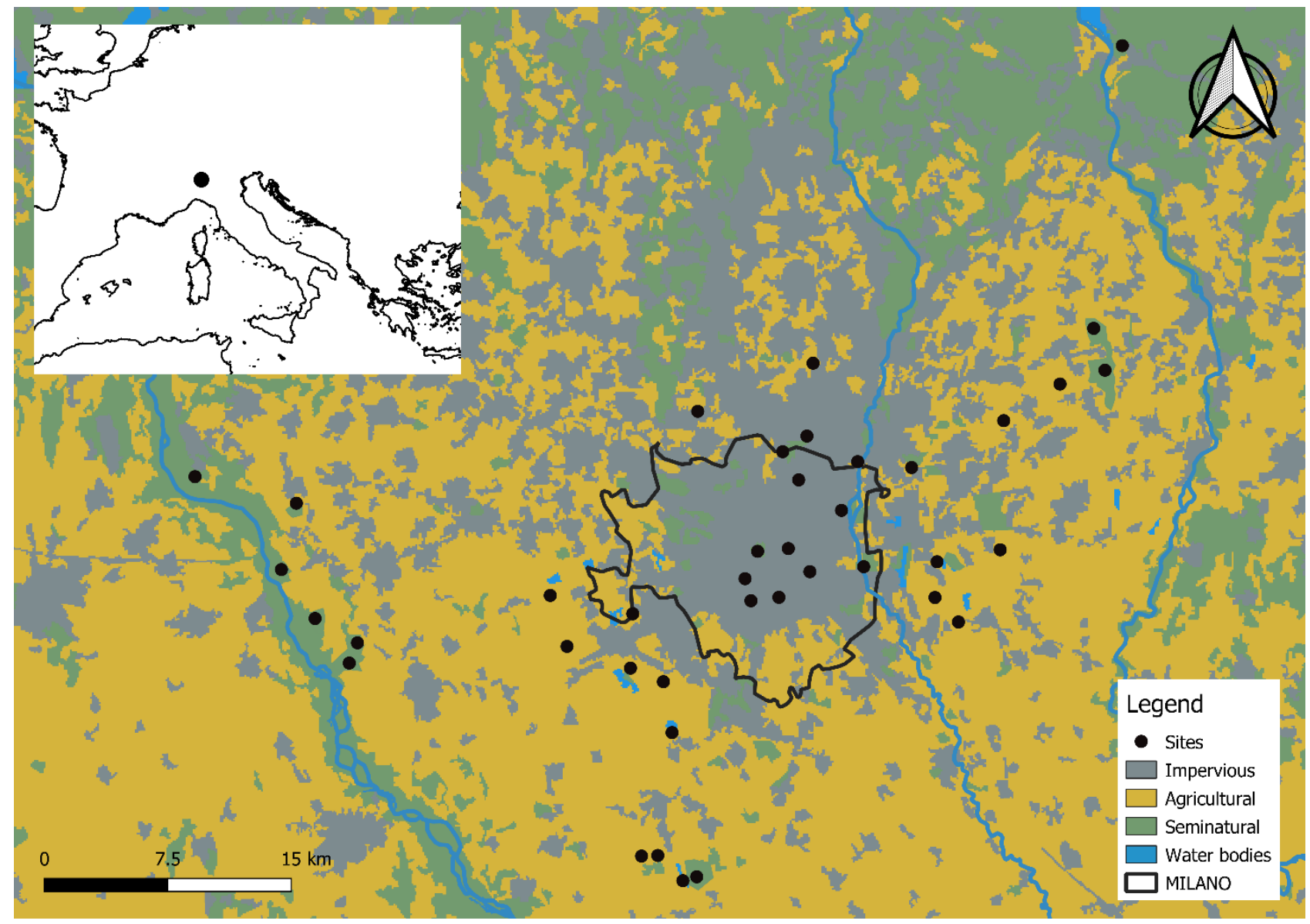

Figure 1 - Sampling sites. The distribution of sampling sites along a gradient of increasing urbanization in Northern Italy. The map also shows the Municipality of Milan, three major rivers and the main land uses of this region.

\section{Landscape and local climate characterization}

To characterize landscape composition, we measured the cover percentage of impervious (concretedominated) surfaces, urban green areas and seminatural lands (forests and hay meadows). To describe landscape configuration we focused on green and seminatural patches together and calculated Edge density 
(ED), the Euclidean nearest neighbor distance (ENN), and also the size of urban parks. ED measures the total length of all edge segments per area unit and describes the fragmentation in size of the patches (i.e., highly fragmented when the perimeter is high relative to their area), while ENN describes the mean distance between patches in the landscape.

Temperature and precipitation vary with urbanization (see Figs S2-S3), we used 3-months averages of hourly temperature at 2-m and hourly precipitation sum between February and July 2019. We calculated an index of temperature seasonality as the coefficient of variation between spring and summer. Air temperature data were also used to calculate the Growing Season Suitability index (GSS), quantifying the length of the vegetative season that, together with precipitation, could impact the productivity of plant resources. All used variables were extracted from circular buffers of $1 \mathrm{~km}$ around the sampling sites, further methodological details are available in Appendix A1.

\section{Pollinator abundance}

Sampling of pollinator abundances took place during the peak flowering period for the study area, from midMay to mid-June 2019, in 36 of the original 40 sites. Passive sampling took place for 24 hours at each site, with pan and sticky traps, that are complementary methods for sampling the same target insect groups. The pan trap consisted of a wooden stick holding three pan traps of yellow, blue and white bowls with UV reflection, containing water with 1-2 $\mathrm{mL}$ of soap to reduce surface tension, and the bowls height was adjusted specifically depending on grass tallness, so that the trap would be slightly higher than the height of the grass (Popic et al. 2013). Sticky traps were $15 * 20 \mathrm{~cm}$ yellow plastic board placed on poles at $1 \mathrm{~m}$ height on which pollinating insects remain glued (Sutherland et al. 2001). In each site, three sets of pan-traps were placed 10 $\mathrm{m}$ apart from each other; and five yellow sticky traps were placed at $5 \mathrm{~m}$ from the pan-traps. In this study, we counted the total abundance of bees and hoverflies (Hymenoptera: Anthophila and Diptera: Syrphidae) following (Bates et al. 2011). We did not count honeybees since their numerosity is only due to beehives in the vicinities. In the statistical analyses that followed we kept wild bees and hoverflies together and evaluated their total abundance as they belong to the same guild of pollinators (see Fig. S4). 


\section{Nectar sugar quantification}

Standing crop of sugar mass in the nectar was measured from mid-May to mid-June in 35 sites. Flowers of two to three most abundant herbaceous flowering species were selected after an inspection of plant relative cover based on the number of stalks. We chose abundant plants as they should offer most of the local resources. Standing crop of nectar sugar mass is a measure of nectar quality available at a given time and it is a function of both plant secretion and of pollinator visitation frequency (Corbet 2003). As in Biella, Akter, et al. (2019), twenty to thirty blooming flowers for each species were taken from individual plants and the internal part of the corolla was washed in distilled water with a $100 \mu \mathrm{l}$ Hamilton syringe, the number of processed flowers was noted, samples were weighed and then frozen. Sugar quantification was performed using a spectrophotometer Cary 60 (Agilent Technologies, USA) and with Sucrose, D-Fructose and D-Glucose kits (Megazyme, Ireland). We used the sugar mass per flower for each given species in subsequent statistical analyses, which was calculated by dividing the sugar mass by the number of washed flowers of a species processed at a site (Biella, Akter, et al. 2019).

\section{Pollen richness with DNA metabarcoding}

In each sampled site, insects foraging on flowers were actively sampled for one hour by hand-netting and then stored in sterile Eppendorf tubes filled with ethanol 70\%. In the laboratory, we randomly chosen a subset of the sampled sites $(\mathrm{N}=25)$ and analyzed the pollen from insect bodies with DNA metabarcoding following the protocol of Biella, Tommasi, et al. (2019). Full details of the laboratory protocol and bioinformatic processing are reported in Appendix A2. For each site, the number of plant species found in the pollen of all flower visitors was used as indication of pollen richness.

\section{Statistical analyses}

Putative predictors were chosen based on the ecological hypotheses outlined above. We used a repeated Kfold cross-validation for choosing if to fit linear or non-linear models by selecting the lowest RMSE (Root Mean Squared Error) between a linear GLM (Generalized Linear Model) and a non-linear GAM (Generalized Additive Model) associated to each predictor, ten repetitions of $\mathrm{K}=10$ were performed and the mean RMSE was used for the evaluation (see Table S1). To exclude collinear variables from the same analyses, we 
calculated the VIF index from preliminary regression models (Variance Inflation Factor, with an exclusion threshold of 4, Table S2) with the R package car (Fox and Weisber 2019). In the regression models listed below, predictors were square rooted to correct variable skewness and they were scaled to avoid different numerical ranges. Statistical significance was tested with likelihood-ratio tests. We analyzed the effects of landscape composition and configuration, and the summer-to-spring temperature seasonality on pollinator abundances in a Generalized Additive Model with the proportion of impervious land fitted with a smooth term, and the ENN and temperature variation as linear terms. These predictors were chosen because impervious cover describes the urbanization, the ENN indicates distance between patches used by pollinators, and temperature seasonality indicates the potential for thermic stress. This regression was fitted with Structural Equation Models (SEM), including the correlated errors between all predictors (Table S2), with the piecewiseSEM package with $\mathrm{R}$ (Lefcheck 2016). In addition, we modelled the relationship between pollinator abundances and urban park size with a GLM with data from urban parks (this predictor was logtransformed). In all cases, a Poisson family was used for error distribution with a log link function.

For sugars mass, we analyzed the effects of landscape variables and the contribution of urban climate. In particular, we fitted the sugar mass per flower as response and the proportion of impervious land, ED, the mean summer precipitation and the GSS as predictors in a Generalized Linear Mixed Model (GLMM), with a Gamma error distribution, the logarithm as a link function, and plant species and site identities as random intercepts. While impervious cover characterize the urbanization, the other variables describe the impact on plant productivity as ED explains the role of patch size on the diversity of plant communities, and the mean summer precipitation and GSS measure the amount of natural watering and length of the favorable season. This regression was fitted with Structural Equation Models (SEM), including the correlated errors between all predictors (Table S2).

We also analyzed the effect of the urban landscape on the transported pollen richness. We used the total pollen richness for each site as response variable in a GLM with the proportion of impervious land and ED as predictors, a Poisson family for error distribution and a log link function. These variables were used because impervious cover indicates the urbanization gradient and ED considers the role of patch size in hosting plant 
diversity, while we did not expect a contribution from seasonal climate on the transported pollen. In addition, we investigated the connection between the geographical origin of plants and the landscape on the plant species of pollen transported. To do so, we used the Fourth Corner analysis to evaluate the relationship between plant incidence measured as the proportion of samples where a plant was found at a given site, plant traits as native of the sampled region, agricultural crop or exotic (Galasso et al. 2018), and site attributes as the proportion of impervious, seminatural and urban green cover. The analysis was performed with ade4 package in R (Thioulouse et al. 2018) by setting 999 permutations of sites and species values for testing significances.

\section{Results}

Pollinator abundances were nonlinearly dependent on the landscape variable of impervious cover, while it decreased linearly with green patches ENN (Table 1, Fig. 2). Pollinator abundance was positively linked to impervious cover until a threshold value of $22 \%$ cover after which the relationship became negative, decreasing by $34 \%$ (Fig. 2A). Increasing green patches ENN were associated with a decline in pollinator abundance of $27 \%$ across the range of the variable (Fig. 2B). Abundances of pollinators positively responded in a linear way to the seasonal variation in mean temperature between spring and summer (Fig. 2C), with the highest thermic seasonality in sites with medium to low impervious cover (see Fig. S2). Specifically, pollinators increased by $45 \%$ across the range of temperature variation. In city parks, the relationship between pollinator abundances and park size was negative (Table 1, Fig. S5), with a decline of $60 \%$ over the range of the studied urban parks $\left(0.02\right.$ to $\left.0.68 \mathrm{~km}^{2}\right)$.

Sugar mass per flower was linearly dependent on impervious cover and on precipitations (Table 1, Figs 3AB). Specifically, sugar mass increased by $91 \%$ across the range of impervious cover. However, it was not significantly dependent on green areas ED, or GSS or precipitation.

Table 1 - Estimated relationship between pollinator abundances, nectar sugar mass available and pollen species richness carried by pollinators and landscape and climatic variables. Significances are obtained with likelihood-ratio tests. SEM stands for Structural Equation Model; ENN indicates the Euclidean Nearest Neighbor distance of the green and seminatural areas; ED is the Edge Density, total length of all edge segments per unit of area; Growing Season Suitability index is indicated with GSS and it is the fraction of days between February and April with mean temperature above $10^{\circ} \mathrm{C}$. 


\begin{tabular}{|c|c|c|c|c|c|}
\hline Response & Model type & Predictor & $\begin{array}{l}\text { Regression } \\
\text { slope }\left(B_{i}\right)\end{array}$ & $\begin{array}{c}\text { Degree of } \\
\text { freedoms; Chi } \\
\text { squared } \chi^{2}\end{array}$ & Significance P \\
\hline \multirow{3}{*}{$\begin{array}{c}\text { Pollinator } \\
\text { Abundances }\end{array}$} & \multirow{3}{*}{$\begin{array}{l}\text { Urbanization } \\
\text { landscape and } \\
\text { climate model } \\
\text { (SEM) }\end{array}$} & $\begin{array}{l}\text { Impervious } \\
\text { land }\end{array}$ & $\begin{array}{c}\text { Smoothed, see } \\
\text { Fig. } 1\end{array}$ & $3.67 ; 57.30$ & $<0.001$ \\
\hline & & ENN & -0.11 & $1 ; 16.25$ & $<0.001$ \\
\hline & & $\begin{array}{c}\text { Temperature } \\
\text { seasonality }\end{array}$ & 0.29 & $1 ; 58.36$ & $<0.001$ \\
\hline $\begin{array}{c}\text { Pollinator } \\
\text { Abundances }\end{array}$ & $\begin{array}{l}\text { Urban parks } \\
\qquad(\mathrm{GLM})\end{array}$ & $\begin{array}{c}\text { Recreational } \\
\text { park size }\end{array}$ & -0.532 & $1 ; 81.467$ & $<0.001$ \\
\hline \multirow{4}{*}{$\begin{array}{c}\text { Nectar sugar } \\
\text { mass }\end{array}$} & \multirow{4}{*}{$\begin{array}{l}\text { Urbanization } \\
\text { landscape and } \\
\text { climate model } \\
\text { (SEM) }\end{array}$} & $\begin{array}{l}\text { Impervious } \\
\text { land }\end{array}$ & 0.89 & $1 ; 6.72$ & $<0.01$ \\
\hline & & ED & -0.37 & $1 ; 2.29$ & 0.13 \\
\hline & & $\begin{array}{c}\text { Summer } \\
\text { precipitation }\end{array}$ & 0.18 & $1 ; 0.92$ & 0.33 \\
\hline & & GSS & -0.25 & $1 ; 1.62$ & 0.20 \\
\hline Pollen richness & $\begin{array}{c}\text { Urbanization } \\
\text { landscape } \\
\text { (GLM) }\end{array}$ & $\begin{array}{l}\text { Impervious } \\
\text { land }\end{array}$ & -0.23 & $1 ; 11.29$ & $<0.001$ \\
\hline
\end{tabular}
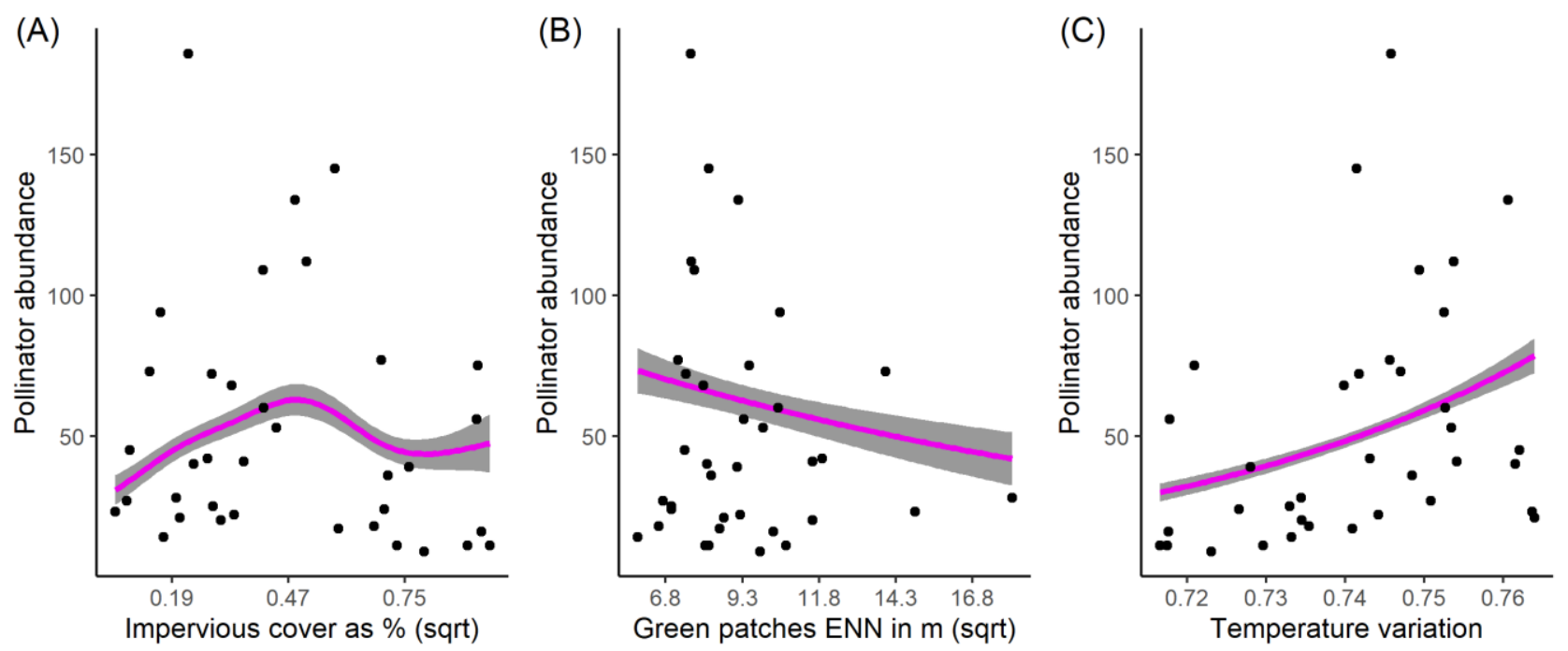

Figure 2 - Pollinator abundances along an urbanization gradient. Relationship of pollinator abundance with (A) impervious cover as a percentage of buffer area and (B) the "ENN", mean distances of green patches; these predictors were square rooted ("sqrt"). (C) Relationship of pollinator abundances with temperature seasonality between spring and summer. Statistical outputs are reported in Table 1. 
The transported pollen richness showed a linear negative relationship with the impervious cover, and specifically by $32.5 \%$ across the range of the variable, and it was not significantly dependent on green areas ED (Table 1, Fig. 4). Most of the species in the pollen transported by pollinators were native to the region (66.1\%). The incidence of exotic plants in the pollen samples was significantly higher at sites with higher cover of urban green areas (Table 2).

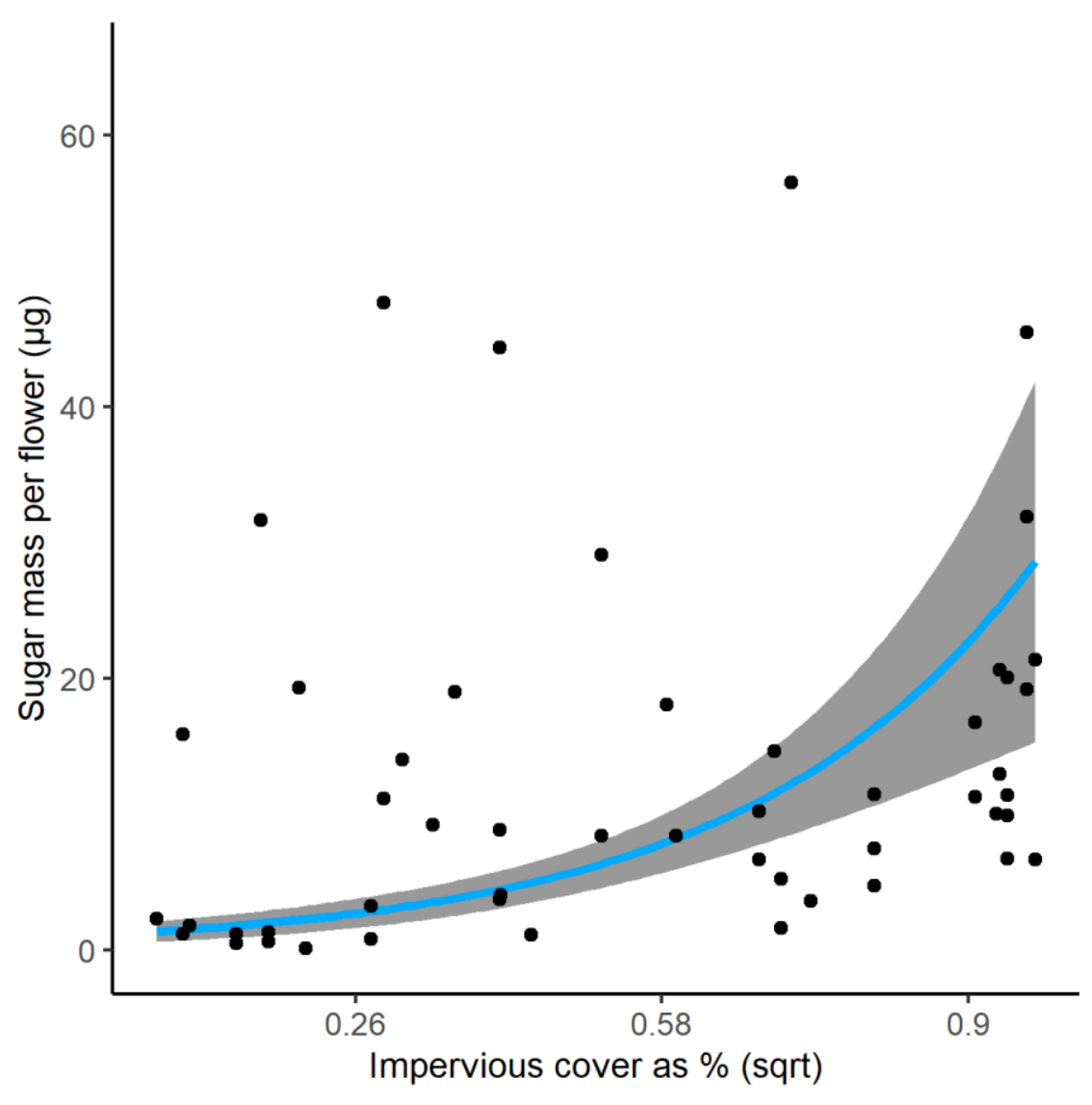

Figure 3 - Sugar mass in nectars along an urbanization gradient. The relationship of sugar mass (standing crop) per flower with impervious cover as a percentage of buffer area is shown. This predictor was square rooted ("sqrt"). The statistical outputs are in Table 1. 


\section{Transported pollen and landscape}

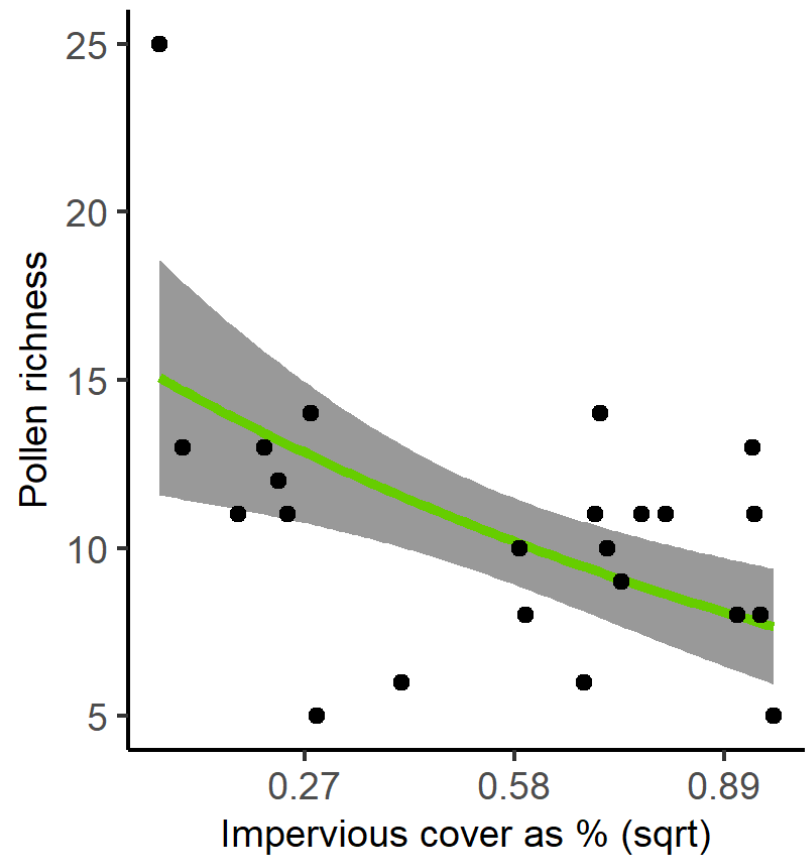

Figure 4 - Plant species richness in pollen from flower-visitor along an urbanization. The relationship between pollen richness for each site and impervious cover measured as surface percentage, in circular buffers of $1 \mathrm{~km}$. This variable was square rooted ("sqrt"). The statistical outputs are indicated in Table 1.

Table2 - The relationships between the type of plant species found in the pollen and landscape composition. Plants are indicated as "Native", "Crops" or "Exotic". Results of a Fourth corner analysis are shown, based on the frequency of plant presence in pollinator samples of each site.

\begin{tabular}{|c|c|c|c|}
\hline Land use cover & Plant origin & Fourth corner statistic r & P value \\
\hline Green areas & Exotic & 0.203 & $\mathbf{0 . 0 2 5}$ \\
\hline Impervious & Exotic & 0.139 & 0.205 \\
\hline Seminatural & Exotic & -0.194 & 0.077 \\
\hline Green areas & Native & -0.156 & 0.115 \\
\hline Impervious & Native & -0.076 & 0.499 \\
\hline Seminatural & Native & 0.188 & 0.091 \\
\hline Green areas & Crop & -0.036 & 0.696 \\
\hline Impervious & Crop & -0.074 & 0.432 \\
\hline Seminatural & Crop & -0.025 & 0.77 \\
\hline
\end{tabular}




\section{Discussion}

Along the gradient of urbanization, landscape composition impacted pollinator abundance in non-linear ways. At low-to-medium levels of impervious cover, the pollinators were increasingly more abundant with urbanization, but landscapes with impervious surfaces higher than $22 \%$ in cover negatively impacted pollinator abundance. This threshold is comparable with another study from North America where butterfly abundance decreased when more than $25 \%$ of impervious cover occurred (Kurylo et al. 2020). Thus, cities are not homogenous entities, but some parts of the urban gradient may benefit pollinators (i.e. suburban areas) while others such as the heavily urbanized city cores do not, a pattern already observed in other studies (Banaszak-Cibicka and Żmihorski 2020; Buchholz and Egerer 2020). Interestingly, pollinators were lowly abundant even at very low impervious cover, perhaps either due to pollinator-unfriendly practices (e.g. agrochemicals, mechanical disturbance, low wildflower cover and diversity) or because pollinator individuals are diluted over large open areas (Holzschuh et al. 2016). Moreover, the isolation of green patches negatively influenced pollinator abundances, in a linear way. This clearly indicates that the dispersion of green patches across a landscape may severely impact local pollinator abundances. This result recalls other studies showing that small and medium sized bees forage at close vicinities, for instance at maximal distance of $150 \mathrm{~m}$ (Hofmann et al. 2020; Zurbuchen et al. 2010). However, these studies were conducted in open landscapes, but in a urban setting it may be reasonable to expect lower home ranges given the presence of vertical obstacles (Harrison and Winfree 2015). Not only the type of landscape but also the size of city parks impacted pollinator abundances, as we recorded fewer pollinators with increasing park size. This result is comparable to what previously found in UK and in Germany (Baldock et al. 2019; Daniels et al. 2020). This may be due to low habitat quality (Bates et al. 2011) or a low population size diluted over a large area (Holzschuh et al. 2016). In spite of all these relationships, local conditions may play an important role in mitigating negative landscape impacts when nesting possibility and flowering resources are high (Delaney et al. 2020; Tommasi et al. 2021).

Temperatures also varied along the artificial gradient. Our analyses showed that pollinator abundances increased linearly with a rising temperature seasonality between spring and summer. This result indicates 
that pollinators are less abundant in sites where the climate is less variable between those seasons, and it contradicts previous ideas suggesting a link between a stable urban climate and pollinators (Baldock 2020). This is corroborated by a previous physiological study showing that wild bee species are affected by a high temperature where the impervious cover is high (Burdine and McCluney 2019). Furthermore, another study showed that bees avoid warmer areas in cities (Hamblin et al. 2018) and that warming may also reduce foraging activities (Kühsel and Blüthgen 2015). All together, these studies and our research indicate that pollinators may be sensitive to the harsh urban climate.

The impervious cover was positively associated with the standing crop of sugar mass available in the nectar of locally abundant plants, although independently to the fragmentation of the green areas (ED). These results showed a higher sugar mass available in urbanized areas than in non-urban sites. This result could be due to either higher secretion rate by plants or due to lower consumption by pollinators in cities (Corbet 2003). The latter possibility seems reasonable given a lower pollinator abundance in the city core that may translate into a lower consumption rate. Conversely, if future actions will increase pollinator abundances even in the core of the city, the foragers will consume more nectar, and this will likely modify the observed trends with impervious surfaces. As it seems that a higher proportion of sugar mass available in cities is a prominent feature of a highly urbanized landscape hosting few pollinators, conservation plans aiming to increase pollinator abundance or richness would impact the nectar pattern observed. It may follow that, as cities provide higher sugar mass, they would sustain high pollinator abundances if the urban landscape was more pollinator friendly. Another relevant aspect to highlight is that nectar availability could vary with plant phenology. Thus, the nectar pattern we observed might be altered by different plants being in flower due to seasonal phenology (Hicks et al. 2016). Plant phenology might even cause seasonal gaps of nectar resources with severe implications for pollinators (Timberlake et al. 2019), and thus our results should be interpreted within the time-frame of our investigation.

In addition to the described patterns in pollinator abundance and nectar, a negative and linear relationship was detected between the impervious cover and the richness of plant species found in the pollen collected by pollinators. This means that the pollen from fewer plant species were transported by the pollinators during 
their foraging trips in highly urbanized sites. As pollen diversity on flower visitor bodies often reflects the local flowering plant diversity (Biella, Tommasi, et al. 2019; Bosch et al. 2009), this result reveals that urban parks of the study area are currently not offering to pollinators as diverse plant resources as areas outside the city. This result could be connected to the low plant diversity usually found in highly urbanized areas (McKinney 2008; Wittig and Becker 2010). Interestingly, we detected a higher incidence of non-native pollen in sites with a higher cover of urban green areas. This indicates that the urbanization deeply shaped the foraging patterns of pollinators, which more frequently visited exotic flowers. Concerningly, pollinators of urban areas carrying less diverse pollen richness, dominated by non-native species, may even have direct implications for plant reproduction (Cohen et al. 2020).

In this study, the urbanization gradient set important scenarios for understanding how plant and pollinators respond to habitat alteration and environmental transitions of urban landscape and climatic features. We detected that the artificial gradient shaped pollinator abundances, pollen species richness transported by flower-visitors and sugar mass available in nectar in linear and nonlinear ways. These factors could have effects on plant reproduction, and on pollinator survival and nutrition. Importantly_this study clarifies that suburban areas, generally characterized by cemented surfaces at medium-low density and green patches of low isolation, host a high pollinator abundance. It is important to note that pollinator abundances are often correlated to species richness (Vereecken et al. 2021), and thus it could be expected to find similar patterns when considering also pollinator richness. However, highly urbanized areas provide nectars richer in available sugars, while the pollen transported was less rich of plant species and frequently with non-native plants, compared to less urbanized areas. As the gradient is human-driven, future actions could modify the responses observed in this study. In particular, managing green areas incorporating practices that are more pollinator-friendly will likely increase pollinator abundances and their activity (Turo and Gardiner 2019). Thus, increasing the suitability of existing and future urban landscapes for plants and pollinators is a priority, given the relevance played for ecosystem services and even for human health (Smith et al. 2015). 


\section{Acknowledgements}

The authors thank local authorities for the sampling permits. The authors also thank Giulia Agostinetto, Davide Magnani, Carola Miuccio, Aidana Nurtaza, Isabel Rondi and Andrea Tapparo for their technical help, and Kathryn Harrold for linguistic revision. This survey was funded by the PIGNOLETTO project, co-financed with the resources of POR FESR 2014-2020, European regional development fund with the contribution of resources from the European Union, Italy and the Lombardy Region. The funder had no role in conducting the research and/or during the preparation of the article.

\section{Author contribution}

PB, ML and AG conceived the ideas and designed methodology; PB, NT, EP, LG collected the data; PB analyzed the data; PB led the writing of the manuscript. All authors contributed critically to the drafts and gave final approval for publication.

\section{References}

Aronson M. F., Piana M. R., Maclvor J. S. \& Pregitzer C. C. (2017) Management of plant diversity in urban green spaces. Urban Biodiversity.

Baldock K. C. R. (2020) Opportunities and threats for pollinator conservation in global towns and cities. Current Opinion in Insect Science doi: 10.1016/j.cois.2020.01.006.

Baldock K. C. R., Goddard M. A., Hicks D. M. et al. (2019) A systems approach reveals urban pollinator hotspots and conservation opportunities. Nature Ecology \& Evolution 3 , 363.

Banaszak-Cibicka W. \& Żmihorski M. (2020) Are cities hotspots for bees? Local and regional diversity patterns lead to different conclusions. Urban Ecosyst doi: 10.1007/s11252-020-00972-w. [online]. Available from: https://doi.org/10.1007/s11252-020-00972-w [Accessed April 19, 2020].

Bartholomée O., Aullo A., Becquet J., Vannier C. \& Lavorel S. (2020) Pollinator presence in orchards depends on landscape-scale habitats more than in-field flower resources. Agriculture, Ecosystems \& Environment doi: 10.1016/j.agee.2019.106806.

Bates A. J., Sadler J. P., Fairbrass A. J., Falk S. J., Hale J. D. \& Matthews T. J. (2011) Changing Bee and Hoverfly Pollinator Assemblages along an Urban-Rural Gradient. PLOS ONE 6, e23459.

Biella P., Akter A., Ollerton J. et al. (2019) Experimental loss of generalist plants reveals alterations in plant-pollinator interactions and a constrained flexibility of foraging. Scientific Reports $9,7376$.

Biella P., Tommasi N., Akter A. et al. (2019) Foraging strategies are maintained despite workforce reduction: A multidisciplinary survey on the pollen collected by a social pollinator. PLOS ONE 14 , e0224037.

Bolger D. T., Suarez A. V., Crooks K. R., Morrison S. A. \& Case T. J. (2000) Arthropods in Urban Habitat Fragments in Southern California: Area, Age, and Edge Effects. Ecological Applications 10 , 1230-1248. 
Bosch J., Martín González A. M., Rodrigo A. \& Navarro D. (2009) Plant-pollinator networks: adding the pollinator's perspective. Ecology Letters 12 , 409-419.

Buchholz S. \& Egerer M. H. (2020) Functional ecology of wild bees in cities: towards a better understanding of trait-urbanization relationships. Biodivers Conserv 29 , 2779-2801.

Burdine J. D. \& McCluney K. E. (2019) Differential sensitivity of bees to urbanization-driven changes in body temperature and water content. Scientific Reports 9, 1643.

Chown S. L. \& Duffy G. A. (2015) Thermal physiology and urbanization: perspectives on exit, entry and transformation rules. Functional Ecology 29, 902-912.

Cohen H., Philpott S. M., Liere H., Lin B. B. \& Jha S. (2020) The relationship between pollinator community and pollination services is mediated by floral abundance in urban landscapes. Urban Ecosyst doi: 10.1007/s11252-020-01024-z.

Colinet H., Sinclair B. J., Vernon P. \& Renault D. (2015) Insects in Fluctuating Thermal Environments. Annual Review of Entomology 60 , 123-140.

Collins C. D., Holt R. D. \& Foster B. L. (2009) Patch size effects on plant species decline in an experimentally fragmented landscape. Ecology $\mathbf{9 0}$ , 2577-2588.

Corbet S. (2003) Nectar sugar content: estimating standing crop and secretion rate in the field.

Apidologie 34, 1-10.

Daniels B., Jedamski J., Ottermanns R. \& RossNickoll M. (2020) A "plan bee" for cities: Pollinator diversity and plant-pollinator interactions in urban green spaces. PLOS ONE 15, e0235492.

Dauber J., Biesmeijer J. C., Gabriel D. et al. (2010) Effects of patch size and density on flower visitation and seed set of wild plants: a panEuropean approach. Journal of Ecology 98 , 188196.
Delaney A., Dembele A., Nombré I. et al. (2020) Local-scale tree and shrub diversity improves pollination services to shea trees in tropical West African parklands. Journal of Applied Ecology 57 , 1504-1513.

Diamond S. E., Dunn R. R., Frank S. D., Haddad N. M. \& Martin R. A. (2015) Shared and unique responses of insects to the interaction of urbanization and background climate. Current Opinion in Insect Science doi: 10.1016/j.cois.2015.10.001.

Faeth S. H. \& Kane T. C. (1978) Urban biogeography : City parks as islands for Diptera and Coleoptera. Oecologia $32,127-133$.

Fisogni A., Hautekèete N., Piquot Y. et al. (2020) Urbanization drives an early spring for plants but not for pollinators. Oikos 129, 1681-1691.

Fox J. \& Weisber S. (2019) An R Companion to Applied Regression. Third. Sage URL: https://socialsciences.mcmaster.ca/jfox/Books/C ompanion/, Thousand Oaks CA.

Galasso G., Conti F., Peruzzi L. et al. (2018) An updated checklist of the vascular flora alien to Italy. Plant Biosystems - An International Journal Dealing with all Aspects of Plant Biology 152 , 556-592.

Geslin B., Gauzens B., Thébault E. \& Dajoz I. (2013) Plant Pollinator Networks along a Gradient of Urbanisation. PLOS ONE 8, e63421.

Hamblin A. L., Youngsteadt E. \& Frank S. D. (2018) Wild bee abundance declines with urban warming, regardless of floral density. Urban Ecosyst 21 , 419-428.

Harrison T. \& Winfree R. (2015) Urban drivers of plant-pollinator interactions. Functional Ecology $29,879-888$.

Hicks D. M., Ouvrard P., Baldock K. C. R. et al. (2016) Food for Pollinators: Quantifying the Nectar and Pollen Resources of Urban Flower Meadows. PLOS ONE 11, e0158117.

Hofmann M. M., Fleischmann A. \& Renner S. S. (2020) Foraging distances in six species of solitary bees with body lengths of 6 to $15 \mathrm{~mm}$, inferred 
from individual tagging, suggest $150 \mathrm{~m}$-rule-ofthumb for flower strip distances. Journal of Hymenoptera Research doi:

10.3897/jhr.77.51182.

Holzschuh A., Dainese M., González-Varo J. P. et al. (2016) Mass-flowering crops dilute pollinator abundance in agricultural landscapes across Europe. Ecology Letters 19 , 1228-1236.

Ibsen P. C., Borowy D., Rochford M., Swan C. M. \& Jenerette G. D. (2020) Influence of Climate and Management on Patterns of Taxonomic and Functional Diversity of Recreational Park Vegetation. Front. Ecol. Evol. doi: 10.3389/fevo.2020.501502. [online]. Available from:

https://www.frontiersin.org/articles/10.3389/fev o.2020.501502/full\#h4 [Accessed August 3, 2021].

Kammerer M., Goslee S. C., Douglas M. R., Tooker J. F. \& Grozinger C. M. (2021) Wild bees as winners and losers: Relative impacts of landscape composition, quality, and climate. Global Change Biology 27, 1250-1265.

Kühsel S. \& Blüthgen N. (2015) High diversity stabilizes the thermal resilience of pollinator communities in intensively managed grasslands. Nature Communications 6, 7989.

Kurylo J. S., Threlfall C. G., Parris K. M., Ossola A., Williams N. S. G. \& Evans K. L. (2020) Butterfly richness and abundance along a gradient of imperviousness and the importance of matrix quality. Ecological Applications 30, e02144.

Kuttler W. (2008) The Urban Climate - Basic and Applied Aspects. In: Urban Ecology: An International Perspective on the Interaction Between Humans and Nature (eds J. M. Marzluff, E. Shulenberger, W. Endlicher, et al.) pp. 233-248 Springer US, Boston, MA. [online]. Available from: https://doi.org/10.1007/978-0-387-73412-5_13 [Accessed November 27, 2020].

Lefcheck J. S. (2016) piecewiseSEM: Piecewise structural equation modelling in $r$ for ecology, evolution, and systematics. Methods in Ecology and Evolution 7 , 573-579.
Lemoine-Rodríguez R., Inostroza L. \& Zepp H. (2020) The global homogenization of urban form. An assessment of 194 cities across time.

Landscape and Urban Planning doi: 10.1016/j.landurbplan.2020.103949.

Marando F., Salvatori E., Sebastiani A., Fusaro L. \& Manes F. (2019) Regulating Ecosystem Services and Green Infrastructure: assessment of Urban Heat Island effect mitigation in the municipality of Rome, Italy. Ecological Modelling doi: 10.1016/j.ecolmodel.2018.11.011.

McKinney M. L. (2008) Effects of urbanization on species richness: A review of plants and animals. Urban Ecosyst 11, 161-176.

Mueller A. L., Berger C. A., Schittenhelm S., Stever-Schoo B. \& Dauber J. (2020) Water availability affects nectar sugar production and insect visitation of the cup plant Silphium perfoliatum L. (Asteraceae). Journal of Agronomy and Crop Science 206 , 529-537.

Neil K. \& Wu J. (2006) Effects of urbanization on plant flowering phenology: A review. Urban Ecosyst 9 , 243-257.

Patel V., Pauli N., Biggs E., Barbour L. \& Boruff B. (2020) Why bees are critical for achieving sustainable development. Ambio doi: 10.1007/s13280-020-01333-9.

Perini K. \& Magliocco A. (2014) Effects of vegetation, urban density, building height, and atmospheric conditions on local temperatures and thermal comfort. Urban Forestry \& Urban Greening 13, 495-506.

Persson A. S., Ekroos J., Olsson P. \& Smith H. G. (2020) Wild bees and hoverflies respond differently to urbanisation, human population density and urban form. Landscape and Urban Planning doi: 10.1016/j.landurbplan.2020.103901.

Phillips B. B., Gaston K. J., Bullock J. M. \& Osborne J. L. (2019) Road verges support pollinators in agricultural landscapes, but are diminished by heavy traffic and summer cutting. Journal of Applied Ecology 56 , 2316-2327. 
Popic T. J., Davila Y. C. \& Wardle G. M. (2013) Evaluation of Common Methods for Sampling Invertebrate Pollinator Assemblages: Net Sampling Out-Perform Pan Traps. PLOS ONE 8 , e66665.

Potts S. G., Imperatriz-Fonseca V., Ngo H. T. et al. (2016) Safeguarding pollinators and their values to human well-being. Nature 540, 220-229.

Regione Lombardia \& ERSAF (2010) Uso del suolo in Regione Lombardia. Regione Lombardia, ERSAF, Milano.

Smith M. R., Singh G. M., Mozaffarian D. \& Myers S. S. (2015) Effects of decreases of animal pollinators on human nutrition and global health: a modelling analysis. The Lancet 386 , 1964-1972.

Steffan-Dewenter I. \& Tscharntke T. (1999) Effects of habitat isolation on pollinator communities and seed set. Oecologia 121 , 432440.

Sutherland J. P., Sullivan M. S. \& Poppy G. M. (2001) Distribution and abundance of aphidophagous hoverflies (Diptera: Syrphidae) in wildflower patches and field margin habitats. Agricultural and Forest Entomology 3, 57-64.

Thioulouse J., Dray S., Dufour A.-B., Siberchicot A., Jombart T. \& Pavoine S. (2018) Multivariate analysis of ecological data with ade4. Springer.

Timberlake T. P., Vaughan I. P. \& Memmott J. (2019) Phenology of farmland floral resources reveals seasonal gaps in nectar availability for bumblebees. Journal of Applied Ecology 56 , 1585-1596.

Tommasi N., Biella P., Guzzetti L. et al. (2021) Impact of land use intensification and local features on plants and pollinators in Sub-Saharan smallholder farms. Agriculture, Ecosystems \& Environment doi: 10.1016/j.agee.2021.107560.
Tonietto R., Fant J., Ascher J., Ellis K. \& Larkin D. (2011) A comparison of bee communities of Chicago green roofs, parks and prairies.

Landscape and Urban Planning 103 , 102-108.

Turo K. J. \& Gardiner M. M. (2019) From potential to practical: conserving bees in urban public green spaces. Frontiers in Ecology and the Environment 17, 167-175.

Vereecken N. J., Weekers T., Leclercq N. et al. (2021) Insect biomass is not a consistent proxy for biodiversity metrics in wild bees. Ecological Indicators doi: 10.1016/j.ecolind.2020.107132.

Wenzel A., Grass I., Belavadi V. V. \& Tscharntke T. (2020) How urbanization is driving pollinator diversity and pollination - A systematic review. Biological Conservation doi: 10.1016/j.biocon.2019.108321.

Wilson C. J. \& Jamieson M. A. (2019) The effects of urbanization on bee communities depends on floral resource availability and bee functional traits. PLOS ONE 14 , e0225852.

Wittig R. \& Becker U. (2010) The spontaneous flora around street trees in cities - A striking example for the worldwide homogenization of the flora of urban habitats. Flora - Morphology, Distribution, Functional Ecology of Plants 205 , 704-709.

Zipper S. C., Schatz J., Singh A., Kucharik C. J., Townsend P. A. \& Loheide S. P. (2016) Urban heat island impacts on plant phenology: intra-urban variability and response to land cover. Environ. Res. Lett. 11, 054023.

Zurbuchen A., Landert L., Klaiber J., Müller A., Hein S. \& Dorn S. (2010) Maximum foraging ranges in solitary bees: only few individuals have the capability to cover long foraging distances. Biological Conservation 143, 669-676. 